\title{
Changes in Oxygen Uptake Rates, Enzyme Activities, Cytochrome Amounts and Adenine Nucleotide Pool Levels during Growth of Acanthamoeba castellanii in Batch Culture
}

\author{
By STEVEN W. EDWARDS AND DAVID LLOYD \\ Department of Microbiology, University College, Newport Road, Cardiff CF2 ITA
}

(Received I3 May I977)

\begin{abstract}
Complex changes in the activities of cytochrome $c$ oxidase, succinate dehydrogenase, catalase, alkaline phosphatase and acid hydrolases, and in the levels of cytochromes were observed during the growth cycle of Acanthamoeba castellanii in a proteose peptone/glucose/ yeast extract medium. A transition occurred at the mid-exponential phase of growth without any change in the growth rate. A second transition corresponded with the cessation of growth; the specific activities of cytochrome $c$ oxidase, succinate dehydrogenase and alkaline phosphatase declined during the stationary phase of growth whereas the specific activities of catalase and the acid hydrolases increased. Glucose was not utilized during the first $30 \mathrm{~h}$ of growth and the respiration rate was low, AMP levels were high and some AMP appeared extracellularly. After $30 \mathrm{~h}$, values for the adenylate charge rose from less than $\mathrm{O} \cdot \mathrm{I}$ to more than $0 \cdot 7$, although ATP levels per cell did not vary. When cells were grown in conditioned medium (obtained by removing cells from a $48 \mathrm{~h}$ culture) the characteristics of a normal culture observed before $30 \mathrm{~h}$ were lost.
\end{abstract}

\section{INTRODUCTION}

The free-living soil amoeba Acanthamoeba castellanii can be induced to encyst under a variety of laboratory conditions (Band, 1963; Neff et al., 1964; Griffiths \& Hughes, 1968; Chagla \& Griffiths, 1974), although the completeness of encystment varies with the method employed. The process is seen as a model for cellular differentiation (Tomlinson \& Jones, 1962; Griffiths, 1970) and although not entirely degradative, large-scale alterations in the subcellular organization of the organism are evident (Bowers \& Korn, 1968, 1969; Griffiths \& Hughes, 1969). The occurrence of lysosomes in Acanthamoeba spp. has been demonstrated (Müller, I969) and the activity of acid phosphatase (a lysosomal marker enzyme) increases in starved cells (Band \& Mohrlok, 1969), encysting cultures (Griffiths \& Bowen, 1969; Bowers \& Korn, I969), and after phagocytosis of latex beads (Wetzel \& Korn, 1969). Thus, in Acanthamoeba, lysosomes function as food vacuoles after phagocytosis and as autolysosomes which are responsible for the internal degradative processes of encysting amoebae.

Termination of exponential growth in non-agitated cultures of $A$. castellanii is thought to be the result of dissolved oxygen concentrations in the culture falling to a limiting level (Byers, Rudick \& Rudick, 1969). These authors also reported that although the specific activity of cytochrome $c$ oxidase increased during the decline phase of growth, the activity per unit of mitochondrial protein remained fairly constant. This finding was interpreted as representing an increase in mitochondrial mass during this period. The cytochrome components of this organism have recently been investigated and have been shown to possess some unusual features, especially those components mediating terminal oxidations 
(Edwards et al., 1977), but how these systems operate during growth has not been reported.

In the present study we have followed the time-course of changes in enzyme activities, cytochrome amounts, oxygen uptake rates and adenine nucleotide pool levels of $A$. castellanii from the early-exponential to the stationary phase of growth, by which time many of the developmental processes involved in encystment may have been initiated. As well as suggesting large-scale variations in organelle activity, the results show that the overall respiratory and energy-yielding processes of the cell are dependent to a large extent on changes in the growth medium.

\section{METHODS}

Growth and harvesting of the organism. Cultures of Acanthamoeba castellanii were maintained and grown at $30{ }^{\circ} \mathrm{C}$ as described previously (Edwards et al., 1977). Harvesting was by centrifuging at $1500 \mathrm{~g}$ for $\mathrm{I} \cdot 5 \mathrm{~min}$. Samples for enzyme or cytochrome analysis were 200 or $100 \mathrm{ml}$ depending on the cell population. Cell pellets were washed once with $5 \mathrm{ml} 50 \mathrm{mM}-\mathrm{MgCl}_{2}, \mathrm{pH} \mathrm{7.4}$, and resuspended to a known density in $50 \mathrm{~mm}$ Tris/ $\mathrm{H}_{2} \mathrm{SO}_{4}$ buffer, $\mathrm{pH} 7.4$, or $0.8 \mathrm{M}$-mannitol. Organisms were counted in a Fuchs-Rosenthal haemocytometer slide (Baird \& Tatlock, Chadwell Heath, Romford, Essex).

Preparation of cell-free extracts. Organisms suspended in the Tris $/ \mathrm{H}_{2} \mathrm{SO}_{4}$ buffer were disrupted ultrasonically for $30 \mathrm{~s} \mathrm{(20} \mathrm{kHz,500} \mathrm{W} \mathrm{MSE} \mathrm{sonicator,} \mathrm{power} \mathrm{setting} \mathrm{5).} \mathrm{This} \mathrm{treatment} \mathrm{resulted} \mathrm{in} 100 \%$ breakage of cells and the suspension thus produced was used as a cell-free extract.

Enzyme assays. Details of enzyme assays are given in Table I. Alkaline phosphatase was assayed at room temperature with a Cary model 14 recording spectrophotometer, fitted with a slide wire with a full scale deflexion corresponding to an extinction of $O \cdot I$. All other spectrophotometric assays were performed with a conventional recording spectrophotometer. Acid hydrolases were assayed at $30^{\circ} \mathrm{C}$ using frozen-thawed extracts; all other assays used freshly prepared extracts. The cell-free extract was diluted in all assays so that the reaction rates were proportional to enzyme concentrations.

Analytical methods. Cytochrome spectra were recorded at $77 \mathrm{~K}$ using frozen-thawed samples of whole cells suspended in $0.8 \mathrm{M}$-mannitol, as described by Edwards et al. (1977), with $\mathrm{K}_{3} \mathrm{Fe}(\mathrm{CN})_{6}$ as oxidant and $\mathrm{Na}_{2} \mathrm{~S}_{2} \mathrm{O}_{4}$ as reductant. Measurements of cytochrome amounts were made using the following wavelength pairs and extinction coefficients: cytochrome $a+a_{3}, 600-630 \mathrm{~nm}, \epsilon_{\mathrm{mm}}=\mathrm{I} 6 \mathrm{~mm}^{-1} \mathrm{~cm}^{-1}$ (Chance \& Williams, 1956); cytochrome $b, 562-570 \mathrm{~nm}, \epsilon_{\mathrm{m}}=19 \mathrm{~mm}^{-1} \mathrm{~cm}^{-1}$ (Ohnishi et al., I 967 ); cytochrome $c, 549-540 \mathrm{~nm}$, $\epsilon_{\mathrm{mM}}=18 \mathrm{~mm}^{-1} \mathrm{~cm}^{-1}$ (Ohnishi et al., 1967 ). Intensification factors of $3.7,6 \cdot \mathrm{I}$ and 13.3 for $c, b$ and $a$-type cytochromes respectively (Edwards $e$ t al., 1977) were used to quantify low temperature spectra. Measurements of adenine nucleotide levels were as described by Edwards, Statham \& Lloyd (1975) using luciferase assays on extracts from I $\mathrm{ml}$ of culture prepared by chloroform extraction. ATP, ADP and AMP were estimated by the method of Chapman, Fall \& Atkinson (1971) using ATP as a calibration standard. Adenine nucleotides in the growth medium were estimated by filtering the culture sample (Whatman GF/A filter) and repeating the above procedure on $\mathrm{I} \mathrm{ml}$ of filtrate. Adenylate charge (Atkinson \& Walton, 1967) is defined as:

$$
\text { Adenylate charge }=\frac{\mathrm{ATP}+\frac{1}{2} \mathrm{ADP}}{\mathrm{ATP}+\mathrm{ADP}+\mathrm{AMP}}
$$

Oxygen uptake was measured polarographically with a Clark electtode (Lloyd \& Brookman, 1967). Protein was estimated by the method of Lowry et al. (195I), with bovine serum albumin as standard. Glucose concentrations in the growth medium were estimated with Sigma reagent kit 5 ro.

Chemicals. Cytochrome $c$ (type III, horse heart), buffered firefly lantern extracts, myokinase (grade III, rabbit muscle), pyruvate kinase (type II, rabbit skeletal muscle), phosphoenolpyruvic acid (sodium salt), ATP (disodium salt), phenazine methosulphate, $p$-nitrophenyl derivatives and Triton $X$-100 were from Sigma. Bovine serum albumin was from Armour Pharmaceuticals, Eastbourne, Sussex.

\section{RESULTS}

\section{Changes in enzyme activities}

Exponential growth occurred with a mean generation time of $10 \mathrm{~h}$ until a stationary phase population of $2 \cdot 2 \times 10^{6}$ organisms $\mathrm{ml}^{-1}$ was attained (Fig. I $a$ ). All enzymes assayed showed complex changes in activity. Cytochrome $c$ oxidase activity varied over a $3 \cdot 5$-fold range with maximum activity after about $45 \mathrm{~h}$ growth and decreased during the stationary phase of growth. Succinate dehydrogenase activity rose to a maximum level 6 to to $\mathrm{h}$ after 


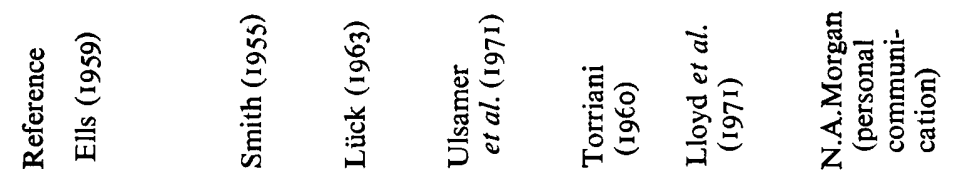

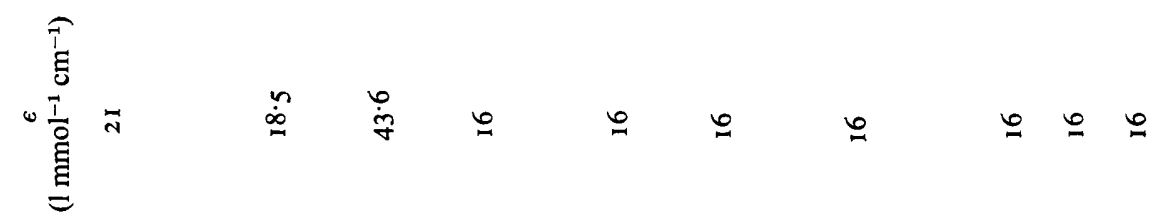

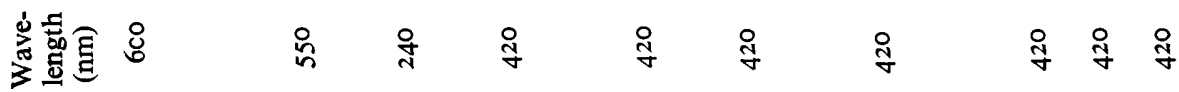

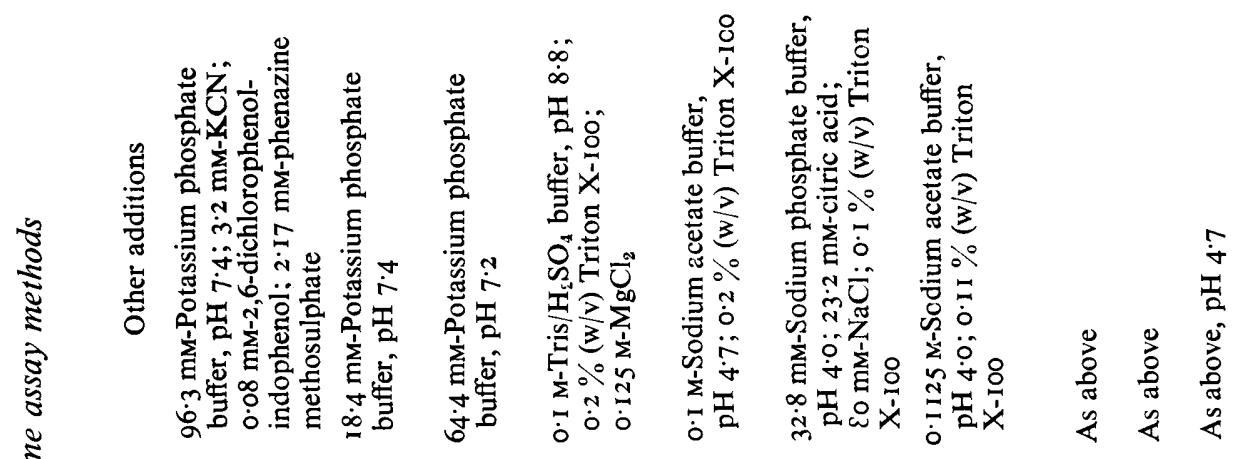

章
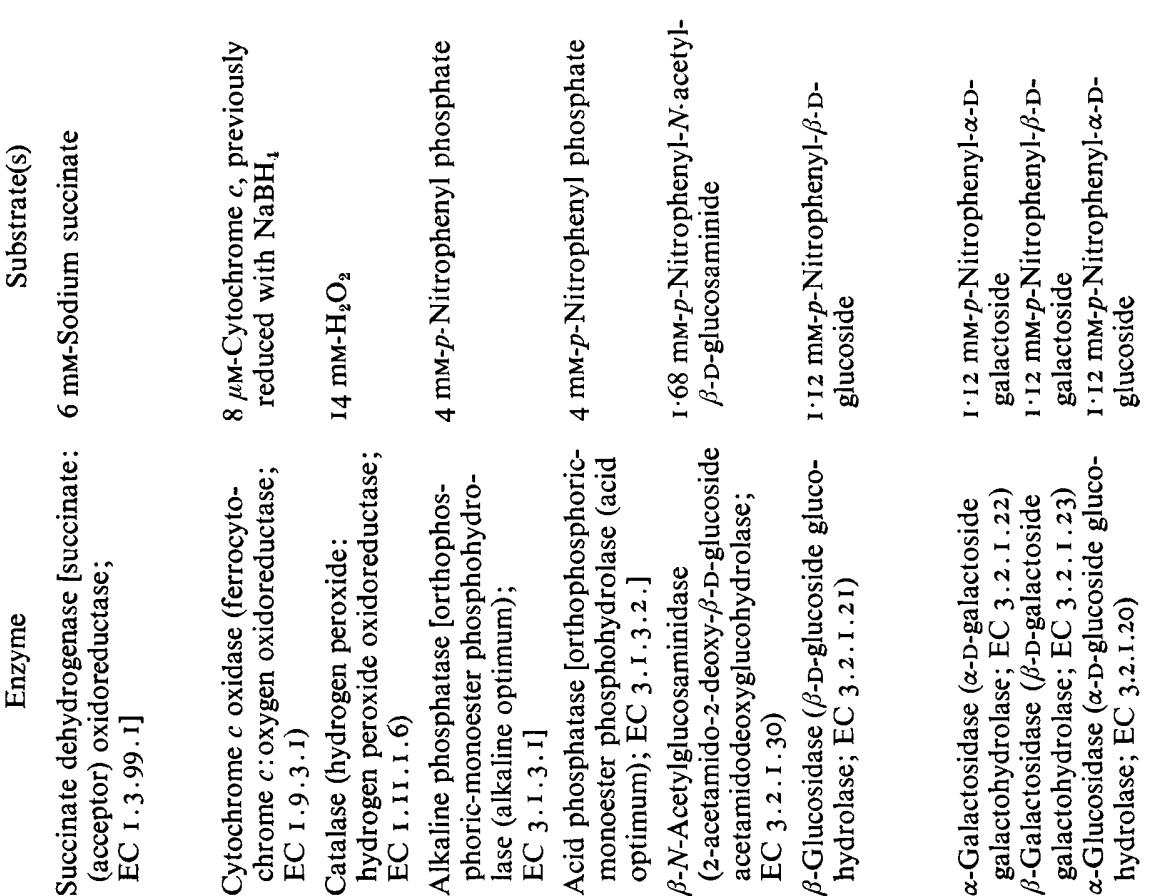


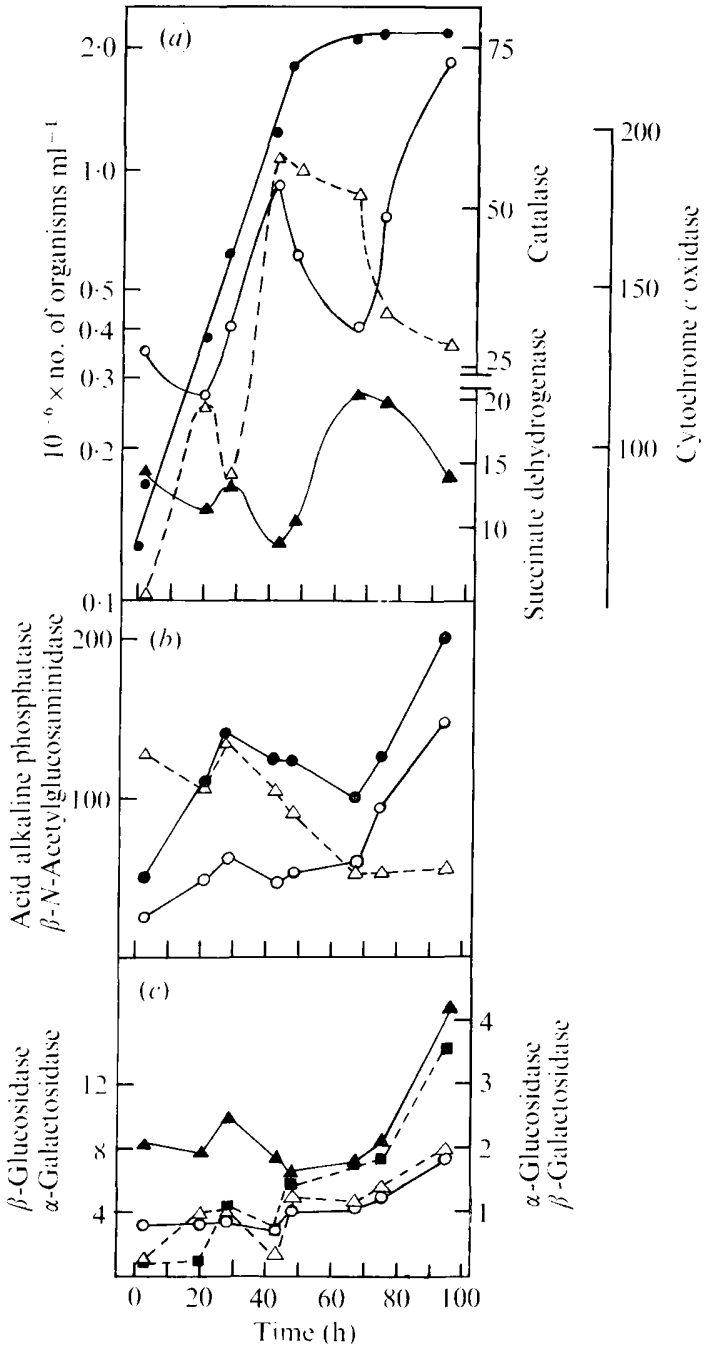

Fig. I

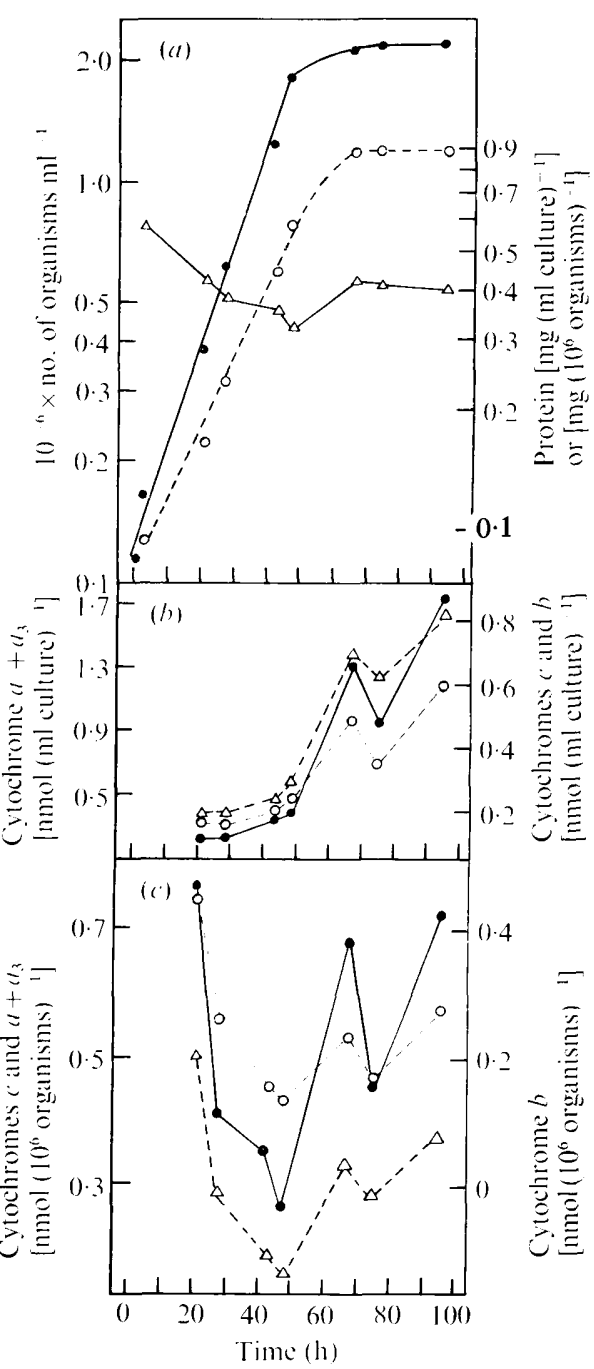

Fig. 2

Fig. I. Changes in enzyme activities during exponential growth of A. castellanii. (a) (O) Cell density; activities of $(\bigcirc)$ catalase, $(\Delta)$ succinate dehydrogenase and $(\triangle)$ cytochrome $c$ oxidase. (b) Activities of $(\bigcirc)$ acid phosphatase, $(\bigcirc) N$-acetyl- $\beta$-D-glucosaminidase and $(\triangle)$ alkaline phosphatase. (c) Activities of $(\bigcirc) \alpha$-galactosidase, (A) $\alpha$-glucosidase, $(\triangle) \beta$-galactosidase and $(\boldsymbol{\square}) \beta$ glucosidase. Enzyme activities are expressed as specific activities [nmol $\mathrm{min}^{-1}$ (mg protein) ${ }^{-1}$ ].

Fig. 2. Changes in protein and cytochrome amounts during exponential growth of $A$. castellanii. (a) (O) Cell density, $(\bigcirc)$ protein concentration $(\mathrm{ml} \text { culture })^{-1}$ and $(\triangle)$ protein concentration

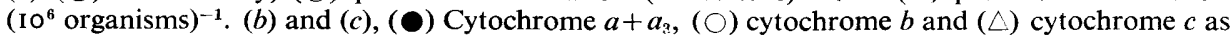
$\mathrm{nmol}$ ( $\mathrm{ml}$ culture $)^{-1}$ and $\mathrm{nmol}\left({ }^{1} 0^{6} \text { organisms) }\right)^{-1}$, respectively.

the onset of stationary phase, whereas catalase activity increased to a maximum at $45 \mathrm{~h}$, declined and then rose sharply during stationary phase. Activities of acid hydrolases all showed similar changes (Fig. I $b, c$ ), rising to maxima after $30 \mathrm{~h}$ growth and again during the stationary phase. However, alkaline phosphatase activity was quite different in that the sharp rise in activity during the stationary phase did not occur. When expressed as enzyme units per cell, the overall profiles did not alter significantly. 


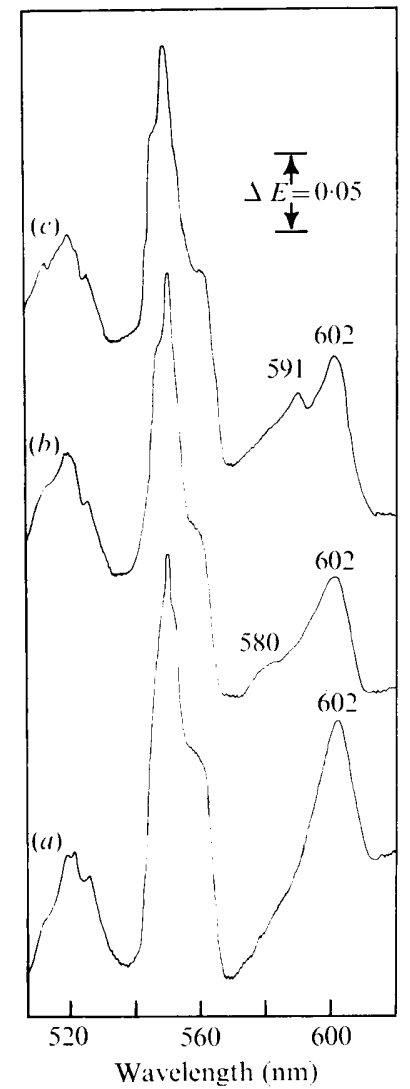

Fig. 3. Difference spectra of whole cells of $A$. castellanii at $77 \mathrm{~K}$. Cells were harvested at different times of growth and suspended in $0.8 \mathrm{M}$-mannitol: $(a) 47 \cdot 25 \mathrm{~h}, \mathrm{I} \cdot 32 \times 10^{8}$ organisms $\mathrm{ml}^{-1},(b) 74 \cdot 25 \mathrm{~h}$, $5.8 \mathrm{I} \times 10^{7}$ organisms ml ${ }^{-1}$ and $(c) 94.25 \mathrm{~h}, 4.4 \times 10^{7}$ organisms $\mathrm{ml}^{-1}$. The path length was $2 \mathrm{~mm}$, the scan speed $1 \mathrm{~nm} \mathrm{~s}^{-1}$ and the spectral band width $\mathrm{I} \mathrm{nm}$.

\section{Measurements of protein and cytochrome amounts}

While the total protein in the culture increased exponentially during exponential growth, it did not parallel cell numbers (Fig. 2a). Protein concentration per cell decreased during this period, increased slightly at the onset of the stationary phase and then continued to fall. The amounts of cytochrome components per $\mathrm{ml}$ culture increased during exponential growth, but showed complex changes during the stationary phase (Fig. $2 b$ ). A decrease in cytochrome content per cell occurred during exponential growth, but again fluctuations during the stationary phase were evident (Fig. 2c). All three types of cytochrome showed similar patterns of changes although some alterations in the ratios of individual components were observed. Marked changes in the nature of the cytochrome components with absorption maxima in the region of 580 to $602 \mathrm{~nm}$ occurred during the stationary phase of growth (Fig. 3); a discrete maximum at 59I $\mathrm{nm}$ was detected after $95 \mathrm{~h}$.

Changes in oxygen uptake rates and adenine nucleotide pool levels

Exponential growth (mean generation time of $8.5 \mathrm{~h}$ ) continued until a stationary population of $7 \times \mathrm{IO}^{6}$ organisms ml ${ }^{-1}$ was attained after $65 \mathrm{~h}$ growth (Fig. 4 a). Apart from a short lag phase $(5 \mathrm{~h})$, there was no detectable change in growth rate during this period. The glucose concentration in the medium did not begin to decrease until after $30 \mathrm{~h}$ when it fell sharply to $30 \mathrm{~mm}$. The dissolved oxygen concentration in the medium fell gradually during 


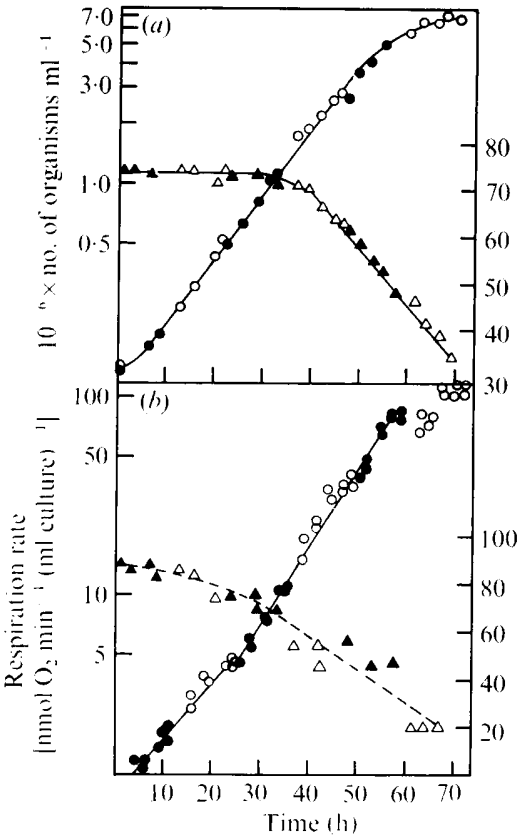

Fig. 4

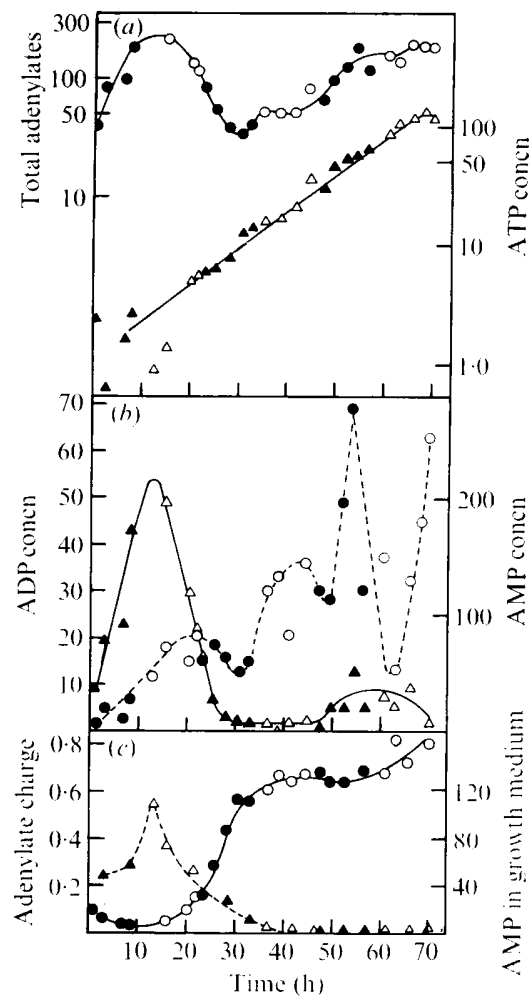

Fig. 5

Fig. 4. Changes in cell population, oxygen uptake rates, dissolved oxygen levels and glucose concentration in the medium during exponential growth of $A$. castellanii. $(a)(\bigcirc, \bigcirc)$ Cell density and $(\triangle, \Delta)$ glucose concentration in the medium. $(b)(\bigcirc, 0)$ Oxygen uptake rates and $(\triangle, \Delta)$ dissolved oxygen concentrations in the medium. Open and closed symbols show the results from two separate experiments.

Fig. 5. Changes in adenine nucleotide pools, total adenylates and adenylate charge during exponential growth of $A$. castellanii. $(a)(\bigcirc, 0)$ Total adenylates and $(\triangle, \Delta)$ ATP. $(b)(\triangle, \Delta)$ AMP and $(\bigcirc, \bigcirc)$ ADP. $(c)(\bigcirc, \bigcirc)$ Adenylate charge and $(\triangle, \Delta)$ AMP in the culture filtrate. All adenylate concentrations are expressed as nmol (ml culture) $)^{-1}$. Open and closed symbols show the results from two separate experiments and times relate to the growth curve in Fig. 4.

growth (Fig. $4 b$ ) and reached about $20 \%$ of air-saturation by $70 \mathrm{~h}$. For the first $25 \mathrm{~h}$, oxygen uptake rates increased exponentially and doubled every II.5 h, but after this period the rate of increase in respiration doubled every $8 \mathrm{~h}$. While ATP content per ml culture increased exponentially with a doubling time of $9.5 \mathrm{~h}$, closely paralleling growth (Fig. 5a), complex changes in ADP and AMP levels were apparent (Fig. $5 b$ ). ADP rose to four maximum levels [increasing from 2 to $70 \mathrm{nmol}$ (ml culture) $)^{-1}$ overall] while AMP levels reached $200 \mathrm{nmol}(\mathrm{ml} \text { culture })^{-1}$ after $\mathrm{I} 3 \mathrm{~h}$, this level falling to $7.5 \mathrm{nmol}$ (ml culture) $)^{-1}$ by $30 \mathrm{~h}$ and remaining fairly low until $50 \mathrm{~h}$. This large amount of AMP resulted in extremely low adenylate charge values (as low as 0.035 ) until $30 \mathrm{~h}$; these values then gradually increased from 0.57 at $30 \mathrm{~h}$ to 0.83 at $70 \mathrm{~h}$ (Fig. $5 \mathrm{c}$ ). Measurements of adenine nucleotides in the filtered culture medium revealed insignificant amounts of ADP or ATP, but large amounts of AMP (uninoculated, autoclaved medium contained only AMP at levels of 2 to $2.5 \mathrm{nmol} \mathrm{ml}^{-1}$ ). However, calculation of adenylate charge after deduction of this amount of AMP in the medium did not significantly alter the low values obtained for the first $30 \mathrm{~h}$. Allowing for extracellular AMP the value was 0.069 instead of 0.048 at $15.5 \mathrm{~h}$; corresponding values for adenylate charge at $33 \mathrm{~h}$ were 0.72 and 0.57 . 


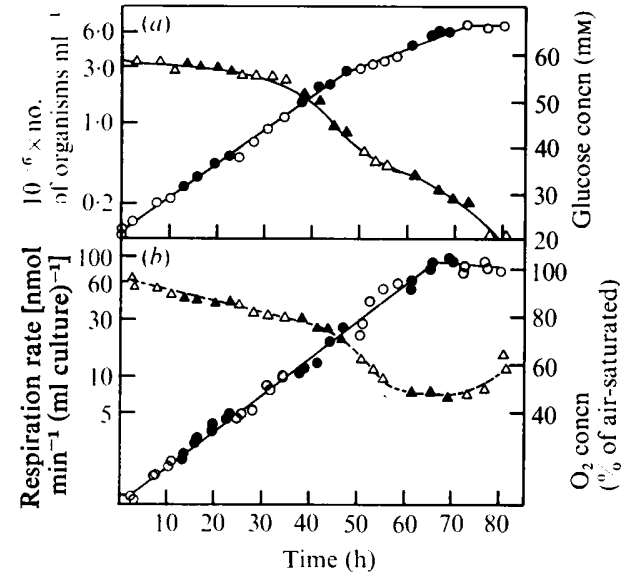

Fig. 6

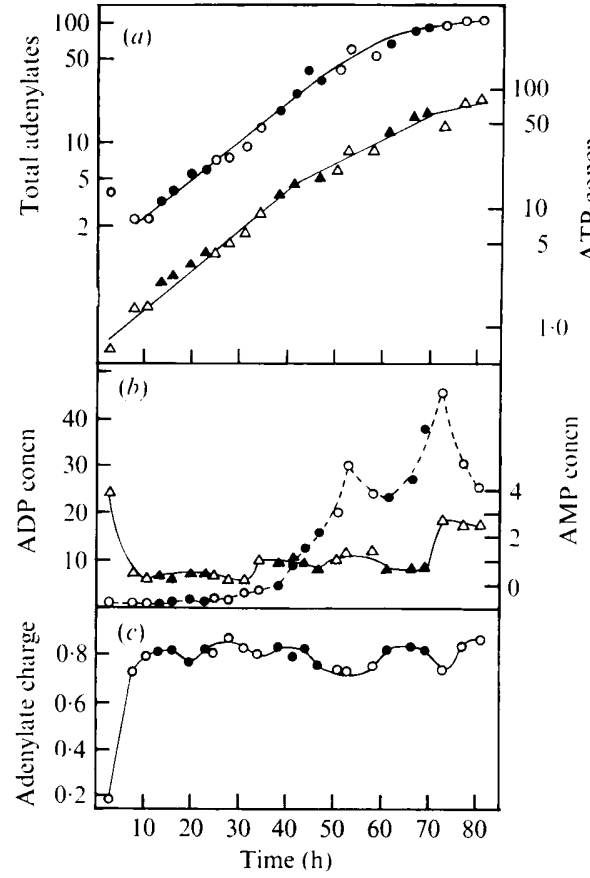

Fig. 7

Fig. 6. Changes in cell population, oxygen uptake rates, dissolved oxygen levels and glucose concentration in the medium during exponential growth of $A$. castellanii in conditioned medium. Cells were inoculated at time zero into medium that had previously supported growth for $48 \mathrm{~h}$. The symbols are as defined in the legend to Fig. 4.

Fig. 7. Changes in adenine nucleotide pools, total adenylates and adenylate charge during exponential growth of $A$. castellanii in conditioned medium. Cells were inoculated into medium that had previously supported growth for $48 \mathrm{~h}$. The symbols are as defined in the legend to Fig. 5 and times relate to the growth curve in Fig. 6.

\section{Changes in oxygen uptake rates and adenine nucleotide pools after inoculation into conditioned medium}

To determine whether some of the above observations were due to changes in the growth medium, amoebae were inoculated into medium which had previously supported growth for $48 \mathrm{~h}$. Cell numbers increased exponentially (mean generation time of $9 \mathrm{~h}$ ) until after $47 \mathrm{~h}$ when the doubling time increased to $18.5 \mathrm{~h}$ until a stationary population of $6.7 \times 10^{6}$ organisms $\mathrm{ml}^{-1}$ was reached after $73 \mathrm{~h}$ (Fig. 6a). During this period the glucose concentration in the medium decreased in two discrete phases to $20 \mathrm{mM}$, beginning to fall initially after $6 \mathrm{~h}$ growth. Oxygen uptake rates increased exponentially until the onset of the stationary phase, when the rate per cell [ $\left.\mathrm{I} \mathrm{nmol} \mathrm{min}^{-1}\left(\mathrm{IO}^{6} \mathrm{cells}\right)^{-1}\right]$ was lower than that of the previous experiment $\left[17 \mathrm{nmol} \mathrm{min}^{-1}\left(\mathrm{IO}^{6} \text { cells }\right)^{-1}\right]$. The dissolved oxygen concentration in the medium decreased during growth to reach $45 \%$ of air-saturation after $65 \mathrm{~h}$, then gradually increased to $60 \%$ by $80 \mathrm{~h}$ (Fig. $6 \mathrm{~b}$ ). This pattern is different from that shown in Fig. $4(\mathrm{~b})$ and results from the lowered oxygen uptake rate per cell in this experiment. ATP levels per $\mathrm{ml}$ culture increased exponentially in two phases, closely paralleling increases in cell numbers (Fig. 7a); total adenylates also closely followed this pattern. ADP levels showed similar changes to those in Fig. $5(b)$ although the values were lower, while the large amounts of AMP previously measured for the first $30 \mathrm{~h}$ were not apparent. No detectable amounts of adenine nucleotides were present in the culture medium at any time. The lowered AMP levels had a significant effect on the adenylate charge (Fig. $7 c$ ), which by $7 \mathrm{~h}$ had reached 
0.73 and oscillated between this value and 0.86 throughout the experiment; these fluctuations appeared to be mainly due to variations in ADP levels.

\section{DISCUSSION}

Exponential growth of $A$. castellanii may be divided into three distinct phases: (i) the first $30 \mathrm{~h}$ after inoculation into fresh medium, when oxygen uptake rates are low. glucose is not utilized and large quantities of AMP are produced, significant amounts of which are found in the medium; (ii) 30 to $60 \mathrm{~h}$ when oxygen uptake rates closely parallel cel Inumbers, which are still increasing exponentially; and (iii) $60 \mathrm{~h}$ onwards when cell division gradually ceases and a stationary population is achieved. Throughout these phases, all enzymes assayed showed complex changes in activity. When cells are inoculated into medium which had previously supported growth for $48 \mathrm{~h}$, three phases can again be distinguished which are quite different from those above: (i) the initial 43 to $48 \mathrm{~h}$ when cell numbers and ATP levels increase exponentially with a doubling time of $9 \mathrm{~h}$; (ii) 48 to $72 \mathrm{~h}$ where these doubling times are 18.5 to $19 \mathrm{~h}$ and (iii) the stationary phase. Thus, when fresh medium is used the onset of the stationary phase is not the result of nutrient depletion, but may be due to the lowered oxygen tension in the medium. It has recently been shown that the respiration rate of $A$. castellanii is reduced by $50 \%$ when the gas phase contains oxygen at $25 \%$ of airsaturation (Edwards et al., I977).

The use of marker enzymes to study organelle development has been well documented (Lloyd, 1974). The increase in cytochrome $c$ oxidase activity (a marker enzyme for the inner mitochondrial membrane) during the late-exponential phase closely agrees with that previously reported (Byers et al., 1969). However, the suggestion by these authors that this represents an increase in mitochondrial mass per cell is not entirely substantiated by measurements of cytochromes. There is, in fact, little correlation between cytochrome $c$ oxidase activity and the measured amount of cytochrome, which has an absorption maximum at $602 \mathrm{~nm}$, assuming that this component is responsible for the oxidation of the cytochrome $c$ present in the enzyme assay. In difference spectra the region of 580 to $605 \mathrm{~nm}$ is complex and contains a number of components, one of which may be cytochrome $a+a_{3}$ (Edwards et al., 1977). After $95 \mathrm{~h}$, two components, with maxima at 591 and $602 \mathrm{~nm}$ are evident in difference spectra. The additional component may represent a degradation product; this could be present throughout growth, but is found in a greater amount at this time since degradative structural alterations within the cell have probably been initiated. Alternative explanations for the presence of this component may be that its own degradation has not yet been effected, or that its synthesis has been increased. Its detectability may also be enhanced by loss of a component at $595 \mathrm{~nm}$.

Acid phosphatase and hydrolases all showed similar patterns of changes in activity, as would be expected since these enzymes are known to be associated with lysosomes (Müller, I969). Two maxima in activity are evident, after $30 \mathrm{~h}$ and in the late-stationary phase. A similar increase in the activity of acid phosphatase in starved cultures of Acanthamoeba rhysodes has been reported (Band \& Mohrlok, 1969) and this is probably concerned with those degradative mechanisms associated with autolysosomes [vacuoles containing acid phosphatase and recognizable cytoplasmic contents (de Duve \& Wattiaux, I966)] which have been identified in encysting amoebae (Bowers \& Korn, 1969). Alkaline phosphatase activity increases at $30 \mathrm{~h}$ but during the stationary phase this activity is reduced to $50 \%$ of that in exponentially growing cultures. This enzyme was believed to be associated with the plasma membrane of $A$. castellanii (Ulsamer et al., 197I), but its location within the contractile vacuole has since been shown by cytochemical techniques (Bowers \& Korn, 1973). Microscopic examination showed that the rate of discharge of water from the contractile vacuole in stationary phase cultures is only half that of exponentially growing cultures (Pal, 1972) and Chambers \& Thompson (1976) have shown that this observation is related to 
a lowered rate of pinocytosis in these cultures. The observations of alkaline phosphatase activity in the present study are in keeping with this idea.

The lowered rate of respiration, the high quantities of AMP in the medium and low adenylate charge are apparently related to a change in the growth medium which is completed by $30 \mathrm{~h}$. Whether the AMP which is excreted into the medium is subsequently degraded or taken up by cells is uncertain. The interpretations of measurements of adenine nucleotides in eukaryotic micro-organisms, where there are separate pools, are limited. However, the vast quantities of AMP excreted into the medium for the initial part of growth may be a response by the cells to control the ATP:ADP or ATP:AMP ratios within the cell, by a similar mechanism to that reported for prokaryotes [see Knowles (I977) for a short review]. Disappearance of glucose from the medium is believed to be via the non-specific process of pinocytosis (Bowers \& Olszewski, 1972). Possibly some other carbon source is used for energy in preference to pinocytotically ingested glucose which is then excreted back into the medium unchanged. Alternatively, for the initial $30 \mathrm{~h}$, pinocytosis may be inhibited and/or phagocytosis of particles (which are observed in the medium after autoclaving) is predominant. This process virtually excludes the uptake of liquid medium (Weisman \& Korn, 1967) and the phagocytotic vesicles produced have high acid phosphatase activity (Wetzel \& Korn, 1969). All lysosomal enzymes showed transient increases in activity at $30 \mathrm{~h}$. Whether phagocytosis is predominant for this period and results in the lowered respiration rates and excretion of AMP into the medium requires further study. Irrespective of the nature of the transition at $30 \mathrm{~h}$ it is remarkable that an organism growing at the maximum rate has an adenylate charge of less than $\mathrm{O} \cdot \mathrm{I}$.

The work was carried out during the tenure of a Medical Research Council Studentship (S.W.E.).

\section{REFERENCES}

Atkinson, D. E. \& Walton, G. M. (1967). Adenosine triphosphate conservation in metabolic regulation. Journal of Biological Chemistry $\mathbf{1 9 3}$, 265-275.

BAND, R. N. (1963). Extrinsic requirements for encystation by the soil amoeba, Hartmannella rhysodes. Journal of Protozoology 10, I0I-I07.

BAND, R. N. \& MOHRLOK, S. (1969). The respiratory metabolism of Acanthamoeba rhysodes during encystation. Journal of General Microbiology 59, $35 \mathrm{I}-358$.

BowERS, B. \& KoRN, E. D. (1968). The fine structure of Acanthamoeba castellanii. I. The trophozoite. Journal of Cell Biology 39, 95-1 I I.

Bowers, B. \& KorN, E. D. (1969). The fine structure of Acanthamoeba castellanii (Neff strain). II. Encystment. Journal of Cell Biology 4r, 786-805.

Bowers, B. \& KorN, E. D. (I973). Cytochemical identification of phosphatase activity in the contractile vacuole of Acanthamoeba castellanii. Journal of Cell Biology 59, 784-79I.

Bowers, B. \& OlszeWSKI, T. E. (1972). Pinocytosis in Acanthamoeba castellanii. Kinetics and morphology. Journal of Cell Biology 53, 68 I-694.

Byers, T. J., Rudick, V. L. \& Rudick, M. J. (1969). Cell size, macromolecular composition, nuclear number, oxygen consumption and cyst formation during two growth phases in unagitated cultures of Acanthamoeba castellanii. Journal of Protozoology 16, 693-699.

Chagla, A. H. \& Griffiths, A. J. (1974). Growth IO and encystation of Acanthamoeba castellanii. Journal of General Microbiology 85, 139-145.

Chambers, J. A. \& Thompson, J. E. (1976). Phagocytosis and pinocytosis in Acanthamoeba castellanii. Journal of General Microbiology 92, 246250.

Chance, B. \& Williams, G. R. (I956). The respiratory chain and oxidative phosphorylation. Advances in Enzymology 17, 65-134.

Chapman, A. G., Fall, L. \& Atkinson, D. E. (1971). Adenosine triphosphate and synchronous mitosis in Physarum polycephalum. Journal of Bacteriology 96, 330-337.

DE Duve, C. \& Wattiaux, R. (I966). Functions of lysosomes. Annual Review of Physiology 28, 435-492.

Edwards, C., Statham, M. \& Lloyd, D. (1975). The preparation of large-scale synchronous cultures of the trypanosomatid, Crithidia fasciculata, by cell-size selection: changes in respiration and adenylate charge through the cell-cycle. Journal of General Microbiology 88, I4 I-I 52.

Edwards, S. W., Chagla, A. H., Griffiths, A. J. \& LloYd, D. (1977). The cytochromes of Acanthamoeba castellanii. Biochemical Journal (in the Press).

Ells, H. A. (1959). A colorimetric method for the assay of soluble succinic dehydrogenase and pyridine nucleotide linked dehydrogenases. Archives of Biochemistry and Biophysics $\mathbf{8 5}$, $56 \mathrm{I}-562$. 
GrIfFITHS, A. J. (1970). Encystment in amoebae. Advances in Microbial Physiology 4, 106-129.

Griffiths, A. J. \& Bowen, S. M. (1969). Lysosomal activity and its control in encysting Hartmannella castellanii. Journal of General Microbiology 59, 239-245.

Griffiths, A. J. \& Hughes, D. E. (I968). Starvation and encystment of a soil amoeba, Hartmannella castellanii.: Journal of Protozoology 15, 673677.

Griffiths, A. J. \& Hughes, D. E. (1969). The physiology of encystment of Hartmannella castellanii. Journal of Protozoology 16, 93-99.

KNowles, C. J. (1977). Microbial regulation by adenine nucleotide pools. Symposia of the Society for General Microbiology 27, 241-283.

LLOYD, D. (1974). Mitochondria of Microorganisms. London, New York: Academic Press.

Lloyd, D., BRIGHTwell, R., Venables, S. E., ROACH, G. I. \& Turner, G. (I97I). Subcellular fractionation of Tetrahymena pyriformis ST by zonal centrifugation: changes in activities and distribution of enzymes during the growth cycle and on starvation. Journal of General Microbiology 65, 209-223.

Lloyd, D. \& Brookman, J. S. G. (I967). An oxygen electrode reaction vessel. Biotechnology and Bioengineering 9, 27 I-272.

Lowry, O. H., Rosebrough, N. J., Farr, A. L. \& RANDALL, R. J. (195I). Protein measurement with the Folin phenol reagent. Journal of Biological Chemistry 193, 265-275.

Lück, H. (1963). Catalase. In Methods of Enzymatic Analysis, vol. I, p. 885 . Edited by H. U. Bergmeyer. New York: Academic Press.

MülleR, M. (1969). Lysosomal hydrolases in
Acanthamoeba sp. Journal of Protozoology 16, 428-43I.

NeFF, R. J., RAY, S. A., Benton, W. F. \& WilboRN, M. (I964). Induction of synchronous encystment (differentiation) in Acanthamoeba sp. Methods in Cell Physiology 1, 55-83.

Ohnishi, T., Kröger, A., Heldt, H. W., Pfaff, E. \& KLIGENBERG, M. (1967). The response of the respiratory chain and adenine nucleotide system to oxidative phosphorylation in yeast mitochondria. European Journal of Biochemistry $\mathbf{r}$, 3OI-3II.

PAL, R. A. (1972). The osmoregulatory system of the amoeba Acanthamoeba castellanii. Journal of Experimental Biology 57, 55-76.

Smith, L. (1955). Cytochromes $a, a_{1}, a_{2}$ and $a_{3}$. Methods in Enzymology 2, 732-740.

Tomlinson, G. \& Jones, E. A. (1962). Cellulose in the cyst wall of a soil amoeba. Biochimica et biophysica acta 63, 194-200.

Torriani, A. (1960). Influence of inorganic phosphate in the formation of phosphatases by Escherichia coli. Biochimica et biophysica acta 38 , 460-468.

Ulsamer, A. G., Wright, P. L., Wetzel, M. G. \& KorN, E. D. (197I). Plasma and phagosome membranes of Acanthamoeba castellanii. Journal of Cell Biology 51, 193-215.

Weisman, R. A. \& Korn, E. D. (1967). Phagocytosis of latex beads by Acanthamoeba. I. Biochemical properties. Biochemistry 6, 485-497.

WeTzel, M. G. \& Korn, E. D. (I969). Phagocytosis of latex beads by Acanthamoeba castellanii (Neff) III. Isolation of the phagocytotic vesicles and their membranes. Journal of Cell Biology 43, 90-I04. 